\title{
Mengatasi perilaku kecanduan game online melalui layanan bimbingan kelompok
}

\author{
Dewi Trisnowati ${ }^{1}$, Anna Rufaidah $\left.^{2 *}\right)$, Nina Mardiana ${ }^{3}$ ) \\ 1,2,3) Universitas Indraprasta PGRI \\ *) anna.rufaidah@unindra.ac.id
}

Article History: Received: $12 / 04 / 2021$; Revised: 30/05/2021; Accepted: 04/06/2021 Published: 28/062021.

How to cite:

Trisnowati, D., Rufaidah, A., \& Mardiana, N. (2021). Mengatasi perilaku kecanduan game online melalui layanan bimbingan kelompok. Orien: Cakrawala Ilmiah Mahasiswa, 1(1), pp. 1724. DOI: $10.30998 /$ ocim.v1i1.458

cc) (i) This is an open access article distributed under the Creative Commons 4.0 Attribution License, which permits unrestricted use, distribution, and reproduction in any medium, provided the original work is properly cited. (C) 2021 , Trisnowati, D., Rufaidah, A., \& Mardiana, $\mathrm{N}$

\begin{abstract}
Abstrak: Penelitian ini bertujuan untuk mengetahui tentang pengaruh layanan bimbingan kelompok melalui media whatsapp dalam mencegah perilaku kecanduan game online siswa SMK Teladan. Metode penelitian yang digunakan penulis adalah metode kuantitaif dengan pendekatan eksperimen dan menggunakan the one grup pretest-posttest design. Data dan sumber data dalam penelitian ini adalah siswa kelas XI di SMK Teladan berjumlah 10 orang dengan menggunakan non probability sampling. Instrumen penelitian yang digunakan dalam penelitian ini adalah kuesioner dengan menggunakan skala likert yang ditujukan kepada siswa. Teknik analisa data dilakukan dengan menggunakan uji statistik deskriptif dan uji hipotesis deskriptif. Uji hipotesis penelitian menggunakan uji wilcoxon signed rank yang diolah menggunakan SPSS 20 for window.
\end{abstract}

Kata Kunci: kecanduan game online, bimbingan kelompok

\begin{abstract}
This study aims to determine the effect of group guidance services in preventing online game addiction behavior in SMK Teladan students. The research method used by the author is a quantitative method with an experimental approach and uses the one group pretest-posttest design. The data and data sources in this study were 10 students of class XI at SMK Teladan using Non Probability Sampling. The research instrument used in this study was a questionnaire using a Likert scale aimed at students/respondents. The data analysis technique was carried out using descriptive statistical tests and descriptive hypothesis testing. The research hypothesis was tested using the wilcoxon signed rank test which was processed using SPSS 20 for window.
\end{abstract}

Keywords: Online game addiction, group guidance

\section{Pendahuluan}

Era revolusi industri 4.0 adalah kondisi dimana kehidupan manusia didominasi oleh kemajuan teknologi informasi, internet, dan teknologi. Kemajuan teknologi juga menciptakan 1001 cara untuk memanfaatkan teknologi sebagai sarana informasi bagi manusia. Teknologi melahirkan sebuah alat yang bisa mempermudah komunikasi yaitu handphone berbasis internet. Dalam survei yang diselenggarakan oleh Asosiasi Penyelenggara Jasa Internet Internet (APJII) mengungkapkan bahwa pengguna jasa internet di Indonesia periode 2019-kuartal II 2020 secara daring naik menjadi 73,7 persen dari populasi atau setara 196,7 juta pengguna. Ketua Umum APJII, menjelaskan kenaikan jumlah penggguna itu antara lain disebabkan beberapa faktor, seperti infrastruktur internet cepat atau broadband di Indonesia semakin merata dengan adanya 
Palapa Ring, transformasi digital semakin masif akibat pembelajaran online dan kebijakan bekerja dari rumah (work form home) akibat pandemi Covid-10 sejak Maret lalu (APJII, 2020).

Asosiasi Penyelenggara Jasa Internet Internet (APJII, 2020) juga mengungkapkan jika game online di akses sebanya 16,5 persen selama masa pandemi ini. Sejatinya, ada lima alasan utama masyarakat mengakses internet, yakni media sosial, komunikasi pesan, game online, dan belanja online (APJII, 2020). Berdasarkan gambaran tersebut, dapat dilihat jika internet berkembang begitu pesat. Tidak hanya untuk browsing dan berinteraksi melalui jejaring sosial. Dengan smartphone berbasis internet apapun bisa digapai oleh manusia baik informasi sampai hiburan.

Smartphone bisa disebut juga dengan ponsel pintar karena senantiasa membuat kita terhubung dengan dunia luar. Namun kemajuan yang dipandang memberikan kemajuan bagi kehidupan manusia dalam kenyataannya memberikan banyak keresahan dan dampak negatif bagi penggunanya yaitu membuat manusia lebih sering berakivitas di dunia maya sehingga menjauhkan sesuatu hal yang nyata. Seperti saat sedang berkumpul dengan keluarga dan teman pada zaman milenial saat ini. Dalam sebuah pertemuan sering ditemukan individu yang sedang berkumpul akan tetapi tetap sibuk dengan smartphone-nya masing-masing. Tidak ada lagi obrolan-obrolan tentang menanyakan kabar tetapi lebih banyak hanya untuk sekedar bermain smartphone, bahkan berkumpul hanya untuk bermain game online.

Pada era digital 4.0 video game dan game online merupakan teknologi yang juga berkembang pesat. Game online, kata yang sering digunakan untuk merepresentasikan sebuah permainan digital yang sedang marak di zaman yang modern ini (Masya \& Candra, 2016). Game online menurut Burhan (Kustiawan, 2019) sebagai game computer yang dimainkan oleh multi pemain melalui internet. Game online merupakan system yang sangat disukai oleh khalayak banyak, baik anak-anak, remaja, maupun orang dewasa. Permainan ini dimainkan secara online dengan dukungan internet, dan dalam bermain game online banyak sekali membuat rasa ingin tahu yang tinggi karena setiap beberapa bulan sekali pihak game online selalu memperbarui aplikasi game online supaya individu mempunyai rasa penasaran yang tinggi, dengan pembaruan yang dilakukan oleh pihak game online tersebut.

Tipe-tipe game online terdiri dari beberapa bentuk diantaranya yaitu (Masya \& Candra, 2016) :

1. First Person Shooter (FPS), game ini mengambil pandangan orang pertama pada gamer-nya sehingga seolah-olah pertama pada gamer-nya sehingga seolah-olah kita sendiri yang berada dalam game tersebut, kebanyakan game ini mengambil setting peperangan dengan senjatasenjata militer (di Indonesia game jenis ini sering disebut game tembak-tembakan).

2. Real-Time Strategy, merupakan game yang permainanya menekankan kepada kehebatan strategi pemainnya, biasanya permainan memainkan tidak hanya 1 karakter saja akan tetapi banyak karakter.

3. Croos-Platform Online, game yang dapat dimainkan secara online dengan hardware yang berbeda misalnya saja need for speed undercorver dapat dimainkan secara online dari PC maupun hardware/console game yang memiliki konektivitas ke internet sehingga dapat bermain secara online).

4. Browser games, merupakan game yang dimainkan pada browser seperti firefox, opera, IE. Syarat dimana sebuah browser dapat memainkan game ini adalah browser sudah mendukung javascript, php, maupun flash.

5. Massive Multiplayer Online Games adalah game dimana pemain bermain dalam dunia yang skalanya besar (>100 pemain), setiap pemain dapat berinteraksi langsung seperti halnya dunia nyata. 
Game online merupakan sebuah fenomena yang harus diperhatikan, karena berpotensi menimbulkan perilaku adiksi pada para penggunanya. Kecanduan atau addiction dalam kamus psikologis diartikan sebagai ketergantungan secara fisik pada suatu obat bius, keanduan tersebut menambah toleransi terhadap obat bius, ketergantungan fisik dan psikologis dan menambah pengasingan diri dari masyarakat apabila obat dihentikan, biasanya digunakan dalam konteks klinis dan diperhalus dengan perilaku berlebihan (Chaplin, 2011). Adiksi game online adalah ketergantungan individu secara berlebihan terhadap game online dengan ingin melakukan secara terus-menerus yang pada akhirnya menimbulkan efek negatif pada fisik maupun psikologis individu (Fitri, Erwinda, \& Ifdil, 2018).

Game online akan berdampak positif apabila dimanfaatkan untuk hiburan (Adams, 2013) di mana segala rasa penat dan stres dapat dikurangi dengan bermain game (Russoniello, O'Brien, \& Parks, 2009). Di sisi lain, bermain game online secara berlebihan tentu membawa dampak yang negatif, khususnya bagi remaja hal ini dapat berpengaruh terhadap perilaku remaja yang mengarah pada penyimpangan sosial yang berdampak negatif (Ulfa, 2017). Remaja dianggap lebih sering dan lebih rentan terhadap kecanduan game online daripada orang dewasa (Novrialdy, 2019). Masa remaja yang berada pada periode ketidakstabilan, cenderung lebih mudah terjerumus terhadap percobaan hal-hal baru (Jordan \& Andersen, 2016). Masa remaja juga lekat dengan stereotipe periode bermasalah (Hurlock, 2010), yang memungkinkan percobaan terhadap hal baru tersebut berisiko menjadi perilaku bermasalah.

Ketika bermain game online, lazimnya seseorang tidak menyadari bahwa waktunya terbuang sia-sia, baik waktu untuk dirinya sendiri maupun waktu dengan orang lain. Sesorang yang sudah kecanduan game online bisa bermain game dalam sehari lebih dari satu jam, dan akan merasa tidak tenang bila hasrat bermainnya tidak terpenuhi. Dalam beberapa penelitian ditemukan bahwa ketertarikan remaja yang berlebihan terhadap game online yang berakibat kepada kacanduan atau adiksi akan berdampak pada masalah mental emosional (Fitri et al., 2018), Dampak negatif lain dari game online bagi pelajar adalah:

1. Peserta didik akan malas belajar dan sering menggunakan waktu luang mereka untuk bermain game online;

2. Peserta didik akan mencuri curi waktu dari jadwal belajar mereka untuk bermain game online;

3. Waktu untuk belajar dan membantu orang tua sehabis jam sekolah akan hilang karena main game online;

4. Uang jajan atau uang bayar sekolah akan diselewengkan untuk bermain game online;

5. Lupa waktu;

6. Pola makan akan terganggu;

7. Emosional peserta didik juga akan terganggu karena efek game ini;

8. Jadwal beribadah pun kadang akan dilalaikan oleh peserta didik; dan

9. Peserta didik cenderung akan membolos sekolah demi game kesayangan mereka (Masya \& Candra, 2016).

Berdasarkan fenomena yang telah diutarakan, maka semestinya diperlukan berbagai upaya pencegahan agar individu khususnya remaja sebagai peserta didik terhindar dari perilaku kecanduan game online. Upaya pencegahan dapat dilakukan dengan berbagai macam cara, salah satunya melalui layanan Bimbingan dan Konseling (BK) yaitu layanan bimbingan kelompok. Layanan bimbingan kelompok adalah pemberian bantuan melalui format kelompok. Dalam dinamika kelompok interaksi antar individu anggota kelompok membahas secara bersama-sama topik tertentu yang berguna untuk pemahaman dan penanganan permasalahan yang dibahas dalam kelompok dengan interaksi sosial yang intensif dan dinamis dengan harapan tujuantujuan layanan dapat tercapai dengan baik (Dahlia, Badrujaman, \& Marjo, 2019). Corey (2013), 
mengemukakan bimbingan kelompok merupakan tujuan pencegahan (preventive) aktivitas kelompok yang umumnya memiliki fokus membahas masalah-masalah pada bidang pendidikan, karir, sosial, atau pribadi.

Layanan bimbingan kelompok dapat mendorong munculnya motivasi indivdu, berkembangnya perasaan, pikiran wawasan dan sikap terarah khususnya dalam bersosialisai atau komunikasi yang berimbas pada pemecahan masalah individu, sehingga individu yang ada didalam kelompok dapat saling membantu memecahkan permasalahan klien dan dapat berdampak baik, sehingga kemampuan sosialisasi dan komunikasi individu berkembang secara optimal. Melalui upaya inilah, tindakan pencegahan perilaku kecanduan game online dapat dilakukan oleh guru BK.

\section{Metode}

Jenis penelitian yang digunakan dalam penelitian ini adalah dengan menggunakan metode eksperimen dengan jenis the onegrup pretest-posttest design. Yusuf (2017) mengemukakan bahwa penelitian eksperimen the onegrup pretest-posttest design merupakan penelitian yang menggunakan satu kelompok dalam meneliti suatu perilaku yang ingin diteliti. Sehingga dalam penelitian the one grup pretest-posttest design tidak menggunakan kelompok kontrol untuk sebagai bahan pertimbangan keberhasilan suatu penelitian. Penelitian ini dilakukan kepada peserta didik di salah satu Sekolah Menengah Kejuruan daerah Jakarta Selatan dengan populasi sebesar 99 orang dan sampel penelitian sebesar 10 orang. Penentuan sampel menggunakan teknik sampling kuota. Menurut Sugiyono (2016) menentukan sampel kouta menurupakan mengambilan objek penelitian dari populasi yang mempunyai karateristik yang sesuai dengan penelitian hingga jumlah sampel yang digunakan peneliti memenuhi standar peneliti. Pengumpulan data yang digunakan dalam penelitian ini melalui penyebaran instrument berupa kuesioner mengenai perilaku kecanduan game online dengan dua tahap yaitu penyebaran instrumen pre-test dan posttest. Analisis data dilakukan dengan melakukan analisis statistik deskriptif dan melakukan pengujian hipotesis dengan menggunkan uji wilcoxon signed rank yang diolah menggunakan SPSS 20 for window.

\section{Hasil dan Diskusi}

Data di dalam penelitian ini setelah diberikan skor kemudian dibagi ke dalam lima rentang kategori yakni sangat rendah, rendah, sedang, tinggi dan sangat tinggi berdasarkan menggunakan norma kategorisasi (Azwar, 2012) sebagai berikut :

Tabel 1. Kategori Rentang Skor

\begin{tabular}{ll}
\hline Rumus & Kategori \\
\hline$\mu \leq-1,5 \sigma$ & Kategori sangat rendah \\
$-1,5 \sigma<\mu \leq-0,5 \sigma$ & Kategori rendah \\
$-0,5 \sigma<\mu \leq+0,5 \sigma$ & Kategori sedang \\
$+0,5 \sigma<\mu \leq+1,5 \sigma$ & Kategori tinggi \\
$+1,5 \sigma<\mu$ & Kategori sangat tinggi \\
\hline
\end{tabular}

Kategorisasi tingkat perilaku kecanduan game online siswa dilakukan dengan menggunakan norma kategori sebagai berikut : 
Tabel 2. Kategorisasi Skor Perilaku Kecanduan Game Online

\begin{tabular}{llccl}
\hline \multicolumn{1}{c}{$\begin{array}{c}\text { Norma } \\
\text { Kategori Skor }\end{array}$} & Skor & Jumlah Subjek & Kotegori & Kat \\
\hline$\mu \leq-1,5 \sigma$ & $<67$ & 5 & $50 \%$ & Sangat Rendah \\
$-1,5 \sigma<\mu \leq-0,5 \sigma$ & $67-80.5$ & 0 & $0 \%$ & Rendah \\
$-0,5 \sigma<\mu \leq+0,5 \sigma$ & $81-109$ & 1 & $10 \%$ & Sedang \\
$+0,5 \sigma<\mu \leq+1,5 \sigma$ & $95-108.5$ & 0 & $0 \%$ & Tinggi \\
$+1,5 \sigma<\mu$ & 109 & 4 & $40 \%$ & Sangat Tinggi \\
\hline Total & & $\mathbf{1 0}$ & & $\mathbf{1 0 0 \%}$ \\
\hline
\end{tabular}

Sumber: Diolah dari data penelitian, 2021

Berdasarkan tabel 2 di atas maka dapat dijelaskan sebagai berikut :

1. Norma kategori skor sangat rendah terdapat pada nilai $<67$ dengan jumlah jumlah subjek penelitian sebanyak 5 siswa dari 10 siswa yang menjadi sampel yaitu siswa berinisial ENE, ADF,MNR,MZF, dam ZRM.

2. Norma kategori rendah pada nilai 67-80.5 tidak ada siswa yang memiliki kategorisasi perilaku kecanduan yang rendah.

3. Norma kategori skor sedang terdapat pada nilai 81-109 dengan jumlah subjek penelitian sebanyak 1 siswa dari 10 siswa yang menjadi sampel yaitu siswa berinisial ADR

4. Norma kategori tinggi pada nilai 95-108.5 tidak ada siswa yang memiliki kategorisasi perilaku kecanduan yang rendah.

5. Norma kategori skor sangat tinggi terdapat pada nilai 109 dengan jumlah subjek penelitian sebanyak 4 siswa dari 10 siswa yang menjadi sampel yaitu siswa berinisial AAD, MHM, ABC, dan HZA.

Tabel 3. Output Rank

\begin{tabular}{|c|c|c|c|c|}
\hline \multicolumn{5}{|c|}{ Ranks } \\
\hline & & $\mathrm{N}$ & Mean Rank & $\begin{array}{l}\text { Sum of } \\
\text { Ranks }\end{array}$ \\
\hline \multirow[t]{4}{*}{ Posttest-Pretest } & Negative Ranks & $0^{a}$ & .00 & .00 \\
\hline & Positive Ranks & $10^{\mathrm{b}}$ & 5.50 & 55.00 \\
\hline & Ties & $0^{c}$ & & \\
\hline & Total & 10 & & \\
\hline
\end{tabular}

Sumber: Diolah dari data penelitian, 2021

Berdasarkan data pengujian di atas berupa data ouput rank dapat disimpulkan bahwa:

1. Pada negatif rank uji wilcoxon antara hasil pretest (sebelum dilakukan layanan) dengan posttest (sesudah dilakukannya) layanan bimbingan kelompok tidak terdapat pengurangan nilai rank negatif.

2. Pada positif rank uji wilxocon antara hasil pretest (sebelum dilakukan layanan) dengan posttest (sesudah dilakukannya) layanan bimbingan kelompok terdapat penambahan nilai rank positif.

3. Pada ties (kesamaan) nilai pretest dengan posttest dapat dikatakan bahwa nilai pretest dengan posttest tidak ada persamaan pada nilai pengisian pretest dan posttest siwa. 
Tabel 4. Uji Hipotesis Wilxocon Signed Rank

Test Statistics ${ }^{a}$

\begin{tabular}{lr} 
& \multicolumn{2}{c}{$\begin{array}{c}\text { Posttest - } \\
\text { Pretest }\end{array}$} \\
\hline$Z$ & $-2.844^{\mathrm{b}}$ \\
\hline Asymp. Sig. (2-tailed) & .004 \\
\hline \multicolumn{2}{c}{ a. Wilcoxon Signed Ranks Test } \\
b. Based on negative ranks. \\
\multicolumn{2}{c}{ Sumber: Diolah dari data penelitian, 2021}
\end{tabular}

Berdasarkan dasar pengambilan keputusan uji wilcoxon dijelaskan bahwa, jika nilai asymp.sig (2-tailed) < 0,05 maka hipotesis diterima, sedangkan jika jika nilai asymp.sig (2-tailed) > 0,05 maka hipotesis ditolak. Dapat disimpulkan berdasarkan hasil uji hipotesis wilcoxon pada SPSS 25 yang terdapat pada tabel 4 menyatakan bahwa hasil nilai asymp. sig(2-tailed) adalah sebesar 0,004, maka dapat dikatakan bahwa hipotesis diterima, yang artinya terdapat pengaruh layanan bimbingan kelompok dalam mencegah perilaku kecanduan game online.

Setiap orang pada prinsipnya tentu berhak untuk menggunakan waktu luangnya untuk bermain game online sebagai hiburan. Namun pada kenyataannya kegiatan bermain game online seringkali menimbulkan dampak-dampak negatif, apalagi jika dilakukan secara berlebihan sehingga mengakibatkan adanya perilaku adiksi atau kecanduan terhadap game online. Bermain game online secara berlebihan dapat mengakibatkan terbuang waktu secara sia-sia, menimbulkan perilaku agresif baik lebih cepat emosi bahkan dampak bermain game online secara berlebihan membuat siswa menjadi kurang bersosialisai. Terdapat beberapa faktor yang menyebabkan adiksi remaja terhadap bermain game online baik secara internal maupun eksternal.

Menurut Ulfa (2017) perilaku kecanduan game online merupakan salah satu kecanduan yang disebabkan oleh teknologi internet atau yang lebih dikenal dengan internet addictive disorder. Internet addictive disorder merupakan kecanduan yang diakibatkan oleh teknologi internet yang dilakukan secara berulang-ulang dan berlebihan dapat menyebabkan kecanduan, salah satunya adalah computer game addiction (berlebihan dalam bermain game online). Dimana dalam keadaan seperti ini perlu diadakannya tindakan preventif agar siswa mampu tercegah dari perilaku kecanduan game online.

Layanan bimbingan kelompok merupakan salah satu layanan konseling yang berpengaruh untuk mencegah perilaku kecanduan game online. Dinamika kelompok dalam selama kegiatan bimbingan kelompok, dibangun untuk membahas permasalahan-permasalahan dan bagaimana cara untuk mencegah perilaku kecanduan game online. Para peserta layanan yaitu siswa dikatakan mendapat perubahan jika dilihat pada tabel 4, yaitu adanya penambahan pada nilai positive rank. Dengan layanan bimbingan kelompok siswa saling mampu bertukar pikiran, pengalaman, berinteraksi dalam dinamika kelompok, dan memperoleh pengetahuan baru terkait dengan bahaya dampak dari bermain game online secara berlebihan, sehingga dapat memperluas pandangan dan memperbaiki kesalahan-kesalahan yang berpengaruh terhadap perilaku kecanduan game online.

\section{Simpulan}

Berdasarkan data atau hasil penelitian yang telah dilakukan dan setelah melakukan analisis statistik serta uji hipotesis, maka dapat disimpulkan secara umum bahwa pengaruh 
layanan bimbingan kelompok dalam mencegah perilaku kecanduan game online. Secara khususnya adalah terdapat perbedaan, perilaku kecanduan game online siswa sebelum diberikannya layanan bimbingan kelompok (pretest) dan setelah diberikannya perlakuan layanan bimbingan kelompok (posttest). Layanan bimbingan kelompok dapat mencegah perilaku kecanduangan game online dengan saling bertukar pengetahuan, wawasan, serta pengalaman dengan memanfaatkan dinamika kelompok sehingga siswa mampu menerapkannya dikehidupannya sehari-hari dengan dasar pengambilan keputusan uji wilcoxon. Dengan layanan bimbingan kelompok siswa mampu mengetahui pengetahuan baru daru dampak bermain game online, dan bagaimana cara agara bermain game online tidak merugikan masa depan dikemudian hari. Peneliti selanjutnya dapat memberikan pembinaan dengan jenis layanan dan teknik yang berbeda.

\section{Ucapan Terima Kasih}

Penelitian ini tentunya tidak akan berjalan dengan lancar jika tidak disertai dengan adanya dukungan dan bantuan dari pihak-pihak terkait. Untuk itu kami mengucapkan terima kasih kepada pihak sekolah yang dijadikan objek penelitian, teman-teman seperjuangan kelas R8E serta pihak-pihak yang membantu pelaksanaan penelitian ini. Semoga Tuhan Yang Maha Kuasa senantiasa melimpahkan rahmat-Nya kepada kita semua agar segala sesuatu yang direncanakan dapat direalisasikan.

\section{Daftar Rujukan}

Adams, E. (2013). Fundamentals of game design (2nd ed). New York: New Riders Publishing.

Buletin APJII. (2020). Asosiasi Penyelenggara Jasa Internet Indonesia. Retrieved from https://blog.apjii.or.id/index.php/2020/11/09/siaran-pers-pengguna-internet-indonesiahampir-tembus-200-juta-di-2019-q2-2020/

Dahlia, Febri, Aip Badrujaman, and Happy Karlina Marjo. (2019). Layanan Bimbingan Kelompok Dengan Pendekatan Positive Behavior Support Dalam Meningkatkan Kedisiplinan Siswa. Jurnal Edukasi: Jurnal Bimbingan Konseling, 4(2):194.

Fitri, Emria, Lira Erwinda, and Ifdil Ifdil. (2018). Konsep Adiksi Game Online Dan Dampaknya Terhadap Masalah Mental Emosional Remaja Serta Peran Bimbingan Dan Konseling. Jurnal Konseling dan Pendidikan, 6(2): 211-19.

Masya, H. \& Candra, D.A. (2016). Faktor-Faktor Yang Mempengaruhi Perilaku Gangguan Kecanduan Game Online Pada Peserta Didik Kelas X Di Madrasah Aliyah Al Furqon Prabumulih Tahun Pelajaran 2015/2016. Konseli: Jurnal Bimbingan dan Konseling (E-Journal), 3(2): 97-112.

Novrialdy, E. (2019). Kecanduan Game Online Pada Remaja: Dampak Dan Pencegahannya. Buletin Psikologi, 27(2):148.

Ulfa, M. (2017). Effect of Addiction Online Game Center. Jom. Fisip 4(1):1-13.

Russoniello, C. V., O’Brien, K., \& Parks, J. M. (2009). The effectiveness of casual video games in improving mood and decreasing stress. Journal of Cyber Therapy E Rehabilitation, 2(1), 5366.

Sugiyono. 2016. Metode Penelitian Kuantitatif, Kualitatif, R dan D. Jakarta: Alfabeta 
24 Mengatasi perilaku kecanduan game online melalui layanan bimbingan kelompok

Yusuf, A.M. (2017). Metodologi Penelitian Kuantitatif Kualitatif dan Penelitian Gabungan. Jakarta: Kencana.

\section{Competing interests:}

The authors declare that they have no significant competing financial, professional or personal interests that might have influenced the performance or presentation of the work described in this manuscript. 